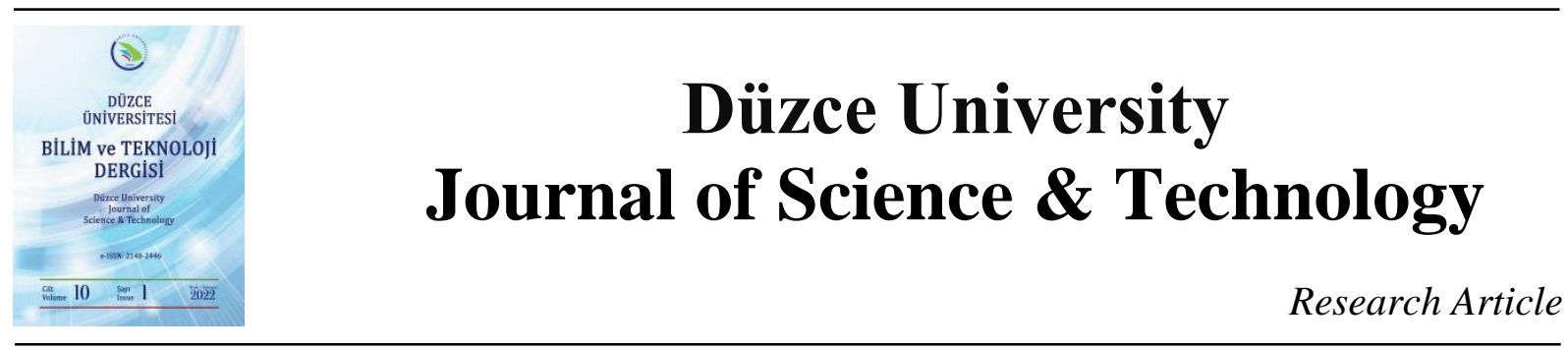

\section{Preparation, Characterization and Investigation of Swelling Behavior of HEMA-Based Amphiphilic Semi-IPN Cryogels Containing Polymeric Linoleic Acid}

\author{
Cansu Meltem GÜREL ${ }^{\mathrm{a}}$, (D) Koray ŞARKAYA ${ }^{\mathrm{b}}$ * (D) Abdülkadir ALLI ${ }^{\mathrm{a}}$ \\ ${ }^{a}$ Department of Chemistry, Faculty of Arts \& Sciences, Düzce University, Düzce, Turkey \\ ${ }^{b}$ Department of Chemistry, Faculty of Arts \& Sciences, Pamukkale University, Denizli, Turkey \\ *Corresponding author's e-mail address: ksarkaya@pau.edu.tr \\ DOI:10.29130/dubited.970641
}

\begin{abstract}
In this study, it was aimed to synthesize and characterize a new polymeric cryogel system to be formed with polymeric linoleic acid (PLina), a vegetable oil-based polymeric fatty acid, and the widely preferred 2-hydroxyethyl methacrylate (HEMA) monomer. cryogels. For this purpose, firstly, autoxidation and hydroxylation reactions were carried out for polymeric lineloic acid, respectively. Hydroxylated polymeric lineloic acid (PLina-OH) and HEMA monomer were subjected to a cryogenic gelation reaction in the presence of $\mathrm{N}, \mathrm{N}^{\prime}$-methylene bisacrylamide (MBAA) as crosslinking agent. The obtained new cryogel was characterized by FTIR, SEM, BET, TGA analyses. The swelling behavior of the synthesized PLinaOH-HEMA cryogels in water was concluded with kinetic studies. In the other hands, some of polar and non-polar other solvents was used for investigation of all cryogels to see their potentials for solvent uptake.
\end{abstract}

Anahtar Kelimeler: Cryogel, Amphiphilic, Semi-IPN, Polimeric lineloic acid

\section{Polimerik Linoleik Asit İçeren HEMA Bazlı Amfifilik Yarı IPN Kriyojellerin Hazırlanması, Karakterizasyonu ve Şişme Davranışının Araştırılması}

\begin{abstract}
ÖZ
$\mathrm{Bu}$ çalışmada, bitkisel yağ bazlı bir polimerik yağ asidi olan polimerik linoleik asit (PLina) ve yaygın olarak tercih edilen 2-hidroksietil metakrilat (HEMA) monomeri ile oluşturulacak yeni bir polimerik kriyojel sisteminin sentezlenmesi ve karakterize edilmesi amaçlanmıştır. Bu amaçla, öncelikle polimerik lineloik asit için sırasıyla otooksidasyon ve hidroksilasyon reaksiyonları gerçekleştirilmiştir. Hidroksillenmiş polimerik lineloik asit ve HEMA monomer, çapraz bağlayıcı olarak MBAA varlığında bir kriyojenik jelleşme reaksiyonuna tabi tutuldu. Elde edilen yeni kriyojeller, FTIR, SEM, BET, TGA analizleri ile karakterize edilmiştir. Sentezlenen PLinaOHHEMA kriyojellerinin sudaki şişme davranışı kinetik çalışmalarla sonuçlandırılmıştır. Öte yandan, tüm kriyojellerin çözücü alımı için potansiyellerini görmek için araştırmak için bazı polar ve polar olmayan diğer çözücüler kullanıldı.
\end{abstract}

Keywords: Kriyojel, Amfifilik, Yart-IPN, Polimerik lineloik asit

Received: 13/07/2021, Revised: 26/07/2021, Accepted: 29/07/2021 


\section{INTRODUCTION}

Polymeric gels are three-dimensional polymer networks crosslinked by physical or chemical interactions [1]. Polymeric gel systems attract the attention of researchers interested in materials science because of their high liquid absorption capacity, their ability to change the volume abruptly due to external stimuli such as $\mathrm{pH}$, temperature, magnetic field, and ionic strength, and their similarity to biological systems [2][3]. In classification of gels, one of the most common classification branches is grouping by solvent type, together with titles such as the structure of the polymer or the type of crosslinking [4]. Hydrogels are known as three-dimensional polymeric gels that swell in water or aqueous solutions [5]. Cryogels are gel matrices synthesized by cryogelation at sub-zero temperatures $\left(-10\right.$ or $\left.-20{ }^{\circ} \mathrm{C}\right)$, and are known as members of a subclass of hydrogels [6]. Thanks to the cryogelation method, macroporous gels (cryogels) with increased mechanical strength and a faster response to stimuli are obtained compared to hydrogels [7], [8]. The sensitivity of conventional hydrogels to environmental stimuli also applies to cryogels, on the contrary, cryogels have large interconnected pore sizes, rapid mass transfer, rapid shrink-swell cycle, good biocompatibility, much elasticity, high mechanical and physical durability [9]. On the other hand, the most obvious difference that distinguishes cryogels from hydrogels is their higher mechanical stability [10]. Hydrogels are soft and brittle when inflated, so the mechanical strength of highly swollen hydrogels is not very strong. Cryogels, on the other hand, show high mechanical strength and elasticity. On the other hand, cryogels are spongy, whereas hydrogels are more gel-like [11]. Thanks to these distinctive features, cryogels have a wide range of applications covering many fields such as biomedicine, biotechnology, environment, health, food, electronics (including ,devices, dielectric studies and sensors) [12]-[19]. Amphiphilic materials contain both hydrophilic and hydrophobic units in their structure. Mostly, they contain surfactants, block copolymers and some important biological molecules [20][21]. Amphiphiles can make phase separation at interfaces and self-assemble in aqueous solution due to their special structure consisting of different hydrophilic and hydrophobic groups [22]. Thus, they can easily form amphiphilic polymer networks. Polymeric hydrogels containing hydrophobic units in addition to hydrophilic units are called amphiphilic polymer hydrogels or amphiphilic polymer networks (APNs) [23]. So, it can create a new platform as consisting of both hydrophilic and hydrophobic moieties in hydrogel structure for use especially in biomedical applications, either. On the other hand, due to the presence of hydrophobic units, amphiphilic hydrogels have improved mechanical properties and adhesion capacity compared to pure (homopolymer) hydrophilic conventional hydrogels [23]. Amphiphilic hydrogels can be synthesized on a natural (biological) or synthetic basis. At this stage, peptides, polysaccharides and organic acids can be used as natural molecules, while commercial monomers can be preferred as synthetic bases. Peptide [24], [25], polysaccharide ( $\alpha$-cyclodextrins [26], chitosan [27], pullulan [28]), or organic acid [29] based amphiphilic hydrogels are the most common of examples for natural sources. It can be prepared with environmentally friendly methods at low costs and, thanks to its biodegradable and renewable material properties, vegetable oils or triglycerides of fatty acids can be considered as alternative comonomer sources for synthesis of amphiphilic hydrogels [30]. Fatty acids can be produced water-soluble as a result of the hydroxylation reaction, thus it earns monomer properties for polymerization reactions [31]. The widespread use of non-biodegradable, petroleum-based polymers is reported to raise many concerns, both economically and environmentally [32]. At this point, there is an increasing interest in biomaterials derived from renewable resources of vegetable oils, such as hydroxy fatty acids. The reason for this is these biopolymers are considered as an alternative source due to the advantages of low cost, ready availability of starting materials and possible biodegradability [33]. Therefore, since vegetable oils are both a renewable material and a suitable source for preparing new raw materials as an alternative to some raw materials of fossil origin, the variety of studies on the evaluation of such sources is increasing day by day [34]. However, chemical modification of polymers has been one of the intensive research topics in recent years, since block/graft copolymers gain amphiphilic, elastomer and/or biodegradable properties depending on the type of different blocks they contain [35]. In parallel with this interest, many new graft copolymers have been synthesized using fatty/fatty acids and various applicable aspects have been studied [36]-[41]. In addition, In the literature, there are studies on hydrogels synthesized by combining oil or fatty acids with synthetic monomers (NIPAM, N- 
isopropylacrylamide) [42]-[44], but there are hardly any studies on cryogels involving the combination of oil or fatty acids and synthetic monomers. 2-Hydroxyethyl Methacrylate (HEMA) is a highly water-soluble, biocompatible, and physicochemically stable monomer and obtained as poly(HEMA) by polymerization as a result of crosslinking under cryogenic conditions [45]. poly(HEMA) cryogels can uptake a high amount of water, so one of their most important properties is their very good swelling behavior [46]. In this study, the main factors are choosing for HEMA as the main monomer are the inert, mechanical resistance, chemical, and biological stability properties of the monomer [47]. "Interlocking Polymer Network (IPN)" are network structures in which one or all of the polymers that make up it are cross-linked and three-dimensional. Each network that creates the IPN can be created at the same time or later. If one of the polymers that make up the IPN is in straightchain structure rather than network structure, it is defined as semi-IPN [48].

The aim of this study is to synthesize a new cryogel by cryopolymerization of HEMA in the presence of Linoleic acid and $N, N$ '-methylene bisacrylamide (MBAA), as crosslinker. It was investigated how physico-chemical and swelling properties of HEMA-based cryogels changed with the increase of Linoleic acid concentration, either.

\section{MATERIALS AND METHODS}

\section{A. 1. Materials}

The chemicals and suppliers for the synthesis of cryogels are as follows: 2-hydroxyethyl methacrylate (HEMA) as monomer, $N, N^{\prime}$-methylene bisacrylamide (MBAA) as crosslinker, as polymerization precursors; reaction accelerator $N, N, N^{\prime}, N^{\prime}$-tetramethylene diamine (TEMED) and initiator ammonium persulfate (APS) were obtained from Sigma Aldrich (Munich, Germany). Chemicals and suppliers for the autoxidation and hydroxylation reaction of linoleic acid are as follows: linoleic acid, petroleum ether (Sigma Aldrich, Munich, Germany), isopropyl alcohol (Carlo Eba, Barcelona, Spain), chloroform and sodium thiosulfate (Merck, Darmstadt, Germany). All chemicals are of analytical purity and have not been subjected to extra purification.

\section{A. 2. Experimental Procedure}

\section{A.2.1. Autoxidation Of Linoleic Acid}

The autoxidation of linoleic acid process was performed as given in the literature [41]. To form polymeric fatty acid, $10 \mathrm{~g}$ of fatty acid was placed in a petri dish (diameter (d):16 cm) and exposed to sunlight for 3 months at room temperature. After 3 months, a viscous liquid with a polymer gel film layer on the surface was obtained. The resulting polymeric fatty acid was kept in chloroform for $24 \mathrm{~h}$ at room temperature and then filtered. The filtrate was evaporated in the evaporator. The resulting viscous liquid was dried in a vacuum oven at $25^{\circ} \mathrm{C}$ for $5 \mathrm{~h}$. The resulting polymeric autooxide fatty acid was stored in the refrigerator $+4{ }^{\circ} \mathrm{C}$ for later use.

\section{A.2.2. Hydroxylation Of Polymeric Linoleic Acid}

The hydroxylation reaction of polymeric linoleic acid with diethanolamine was carried out at $90{ }^{\circ} \mathrm{C}$ for $24 \mathrm{~h}$. To form hydroxylated linoleic acid, 100 grams of fatty acid and $100 \mathrm{ml}$ of diethanolamine were placed in a $500 \mathrm{ml}$ glass flask and treated in an oil bath at $90{ }^{\circ} \mathrm{C}$ for a day. The resulting product was dissolved with the addition of $30 \mathrm{ml}$ acetone, then filtered, and finally precipitated in $100 \mathrm{ml}$ of petroleum ether. Afterwards, it was dried in a vacuum oven at room temperature for a day. Reaction schemes for auto-oxidation and hydroxylation reactions of polymeric linoic acid are presented in Fig. 1. and Fig. 2, respectively. 


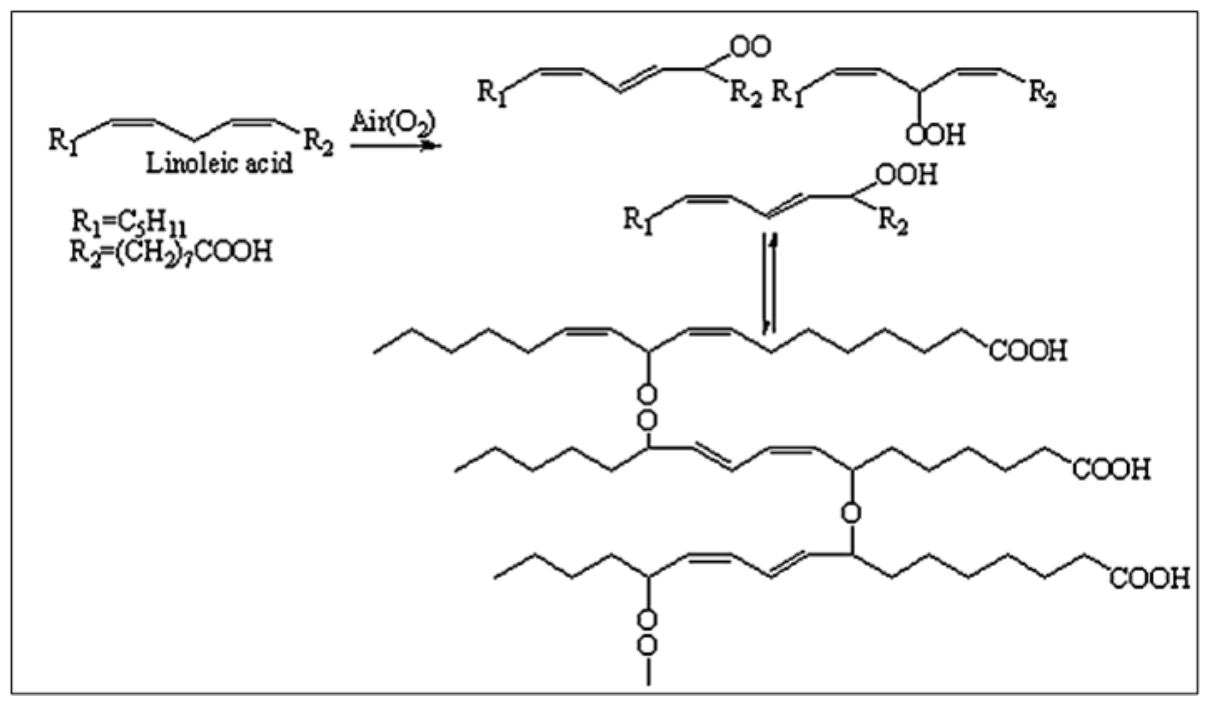

Figure 1. Schematic representation of the auto-oxidation reaction of polymeric linoleic acid

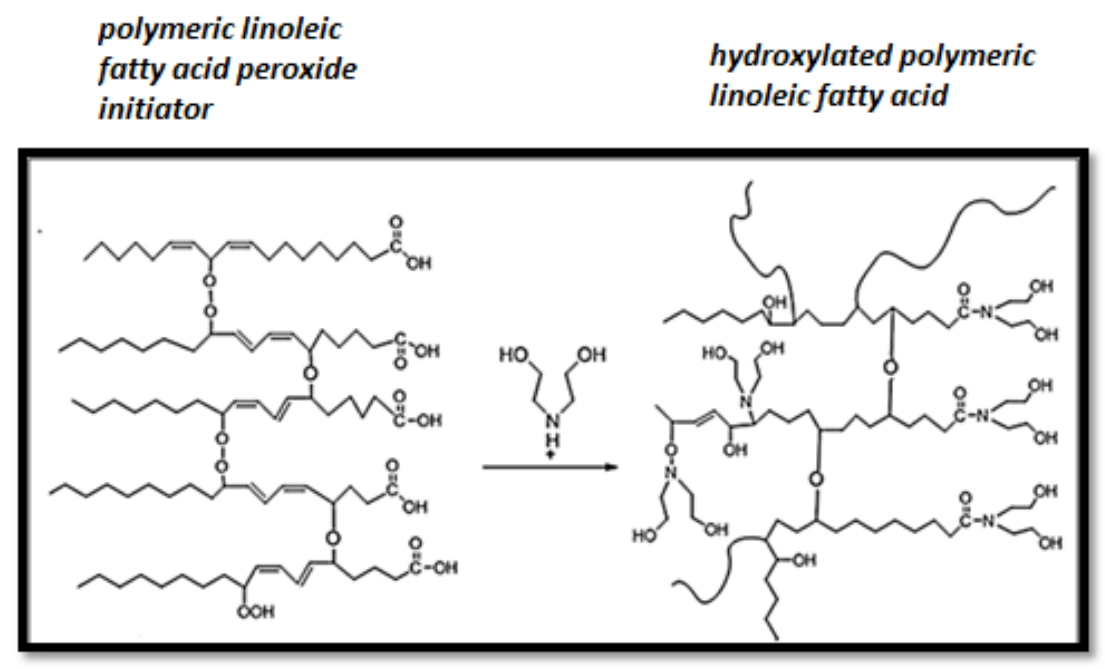

Figure 2. Schematic representation of the hydroxylation reaction of polymeric linoleic acid

\section{A.2.3. Preparation Of Plinaoh-HEMA Amphiphilic Semi-IPN Cryogels}

All cryogels for this study were synthesized in accordance with the procedures in previous study [49]. $100 \mathrm{mg}$ of MBAA was dissolved in $4.60 \mathrm{~mL}$ of water and phase I was formed. Then, $430 \mu \mathrm{L}$ of HEMA monomer was mixed with PLina-OH in different ratios $(20,40,60,80$ and $100 \mathrm{mg}$, respectively) in a plastic tube (phase II), and the resulting mixture was added to phase I. The combined mixture was continued to be stirred in the ice bath for approximately an $\mathrm{h}$ with the help of a magnetic stirrer. Then, $20 \mathrm{mg}$ of APS and $25 \mathrm{ml}$ of TEMED were added to this mixture as the polymerization precursor. The prepared solution for polymerization was poured rapidly into a pre-chilled $0.8 \mathrm{~cm}$ diameter $5 \mathrm{~mL}$ plastic syringes. Plastic syringes containing cryogel solutions were then quickly placed in the freezer at $-18{ }^{\circ} \mathrm{C}$ and held for $24 \mathrm{~h}$. All cryogels, which were taken out of the freezer after $24 \mathrm{~h}$, were taken out of the plastic syringes at room temperature and left to melt for a while, and then washed with distilled water several times to remove the polymerization agents from the reaction medium, assuming that they were not involved in the polymerization reaction, before. Finally, cryogels were cut with a scalpel and stored at $+4{ }^{\circ} \mathrm{C}$ for using in characterization and experimental studies. In order to compare the results, the synthesis of pure HEMA cryogels was performed without 
hydroxylated polymeric linoleic acid addition to polymer matrix towards over same procedure. The code numbers of the cryogels were arranged as $\mathrm{HC} 0, \mathrm{HC} 2, \mathrm{HC} 4, \mathrm{HC} 6, \mathrm{HC} 8$ and $\mathrm{HC} 10$, starting from the pure HEMA-based cryogel to the PLinaOH-HEMA cryogel with the highest concentration of hydroxylated polymeric fatty acids. At this point, the numbers in the codes are related to the number of polymeric fatty acid droplets cryopolymerized with HEMA monomer.

\section{A. 3. Instrumentation And Methods}

Agilent brand Premium Compact NMR device (at Çankırı Karatekin University) with $600 \mathrm{MHz}$ frequency and 14.1 Tesla field strength was used for the determination of the ${ }^{1} \mathrm{H}-\mathrm{NMR}$ spectrum of PLinaOH. In addition, Tetramethylsilane (TMS) was applied as a standard. TOSOH brand UV $(\lambda=254$ $\mathrm{nm}$ ) and EcoSEC HLC-8320 GPC device with RI detector was used for determination of molecular weight of PLinaOH. Characterization studies of cryogels were conducted with spectroscopic, thermal, swelling properties, as well as surface and pore analysis methods. FT-IR spectra of polymer samples were taken to perform spectroscopic characterization of cryogels with the spectroscopic scanning was conducted in the region of $400-4000 \mathrm{~cm}^{-1}$. Fourier Transform Infrared Spectrophotometer (Shimadzu, IRPrestige21) device in Düzce University Scientific and Technological Research Application and Research Center (DUBIT) was used for obtaining FT-IR spectra of cryogels. Thermogravimetric analyzer (TGA) and differential scanning calorimeter (DSC) were applied for the examination of thermal behavior of cryogels. TGA-DSC measurements were acquired at $50 \mathrm{~cm}^{3} / \mathrm{min}$ airflow rate, 20 ${ }^{\circ} \mathrm{C} /$ min temperature increment rate and at the temperature ranges from $0{ }^{\circ} \mathrm{C}$ to $800{ }^{\circ} \mathrm{C}$, via using the device (DSC-TGA: Shimadzu, DTG 60H - DSC 60 in DUBIT). Micrograph images were obtained by using a scanning electron microscope (SEM; FEI, Quanta FEG 250 in DUBIT) device to examine the surface morphology of cryogels. Also, samples were coated with a gold-palladium mixture, before SEM micrographs of polymeric cryogel samples were taken. Hexane, toluene, chloroform, methanol and dimethyl sulfoxide solvents together with distilled water were used for determination of the swelling behavior of the cryogels. In order to determine the swelling properties of the prepared cryogels, the polymer samples were first dried and brought to constant weight. Then, the polymer samples were placed in $25 \mathrm{~mL}$ of distilled water and kept at room temperature for $2 \mathrm{~h}$. Then, the polymer samples were taken from the aqueous medium and the water on the surface was removed by means of moist filter paper and their weights were carried out. These processes were repeated for other solutions as well. The moment the polymeric sample remained in the water was approved as the starting time and at certain time intervals, cryogels were removed from water, and water on the outer surface was dried and weighed with the same precision. Weighing was continued regularly until mass values that did not change over time were obtained, and when the values did not change, experimental procedure was terminated by assuming that swelling reached to equilibrium.

Equilibrium swelling degree, swelling rate and macropore amount (macroporosity) of cryogels were calculated with the help of the following equations Eq (1-2-3) [50]:

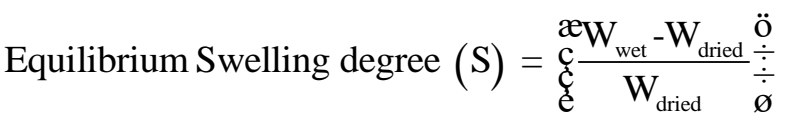

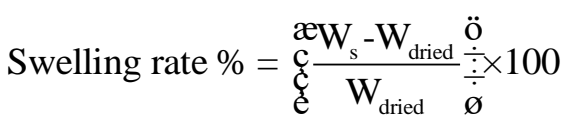

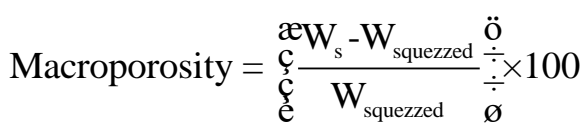

The abbreviations in these calculations are as follows (in gram): $\mathrm{W}_{\mathrm{s}}$; weight of swollen cryogel, $\mathrm{W}_{\text {wet }}$; weight of wet cryogel, $\mathrm{W}_{\text {dried }}$; the dry mass of the cryogel, $\mathrm{W}_{\text {squezzed }}$; weighing of cryogel after mechanical compression. 
The swelling kinetic curves formed as a result of dynamic swelling tests are assumed to be quadratic and the following Eq (4) is applied;

$$
\frac{\mathrm{ds}}{\mathrm{dt}}=\mathrm{k}_{\mathrm{s}}\left(W_{\max }-\mathrm{W}\right)^{2}
$$

In this Eq (4), $\left(\mathrm{d}_{\mathrm{s}} / \mathrm{d}_{\mathrm{t}}\right)$ is swelling rate, $\mathrm{W}_{\max }$ : swelling value of the cryogel at equilibrium degree (from t), $\mathrm{W}$; swelling value at time, $\mathrm{t}$ : time (in $\mathrm{min}$ ), and $\mathrm{k}_{\mathrm{s}}$; swelling rate constant. As a result of the mathematical arrangement of the $\mathrm{Eq}(4)$ for the boundary conditions $\mathrm{S}=0$ for $\mathrm{t}=0$ and $\mathrm{S}=\mathrm{S} \max$ for $\mathrm{t}=\mathrm{t}$;

$\frac{\mathrm{t}}{\mathrm{S}}=\mathrm{A}+\mathrm{Bt}$

In the equation $\mathrm{A}\left(=1 / \mathrm{S}_{\max }{ }^{2} \mathrm{k}_{\mathrm{s}}\right)$; it is the inverse of the initial swelling rate $(1 / \mathrm{ro})$, and $\mathrm{B}(=1 / \mathrm{Smax})$ is the inverse of the maximum swelling value [51].

\section{RESULTS}

Some amount of fatty acids placed in petri dishes with a diameter of $16 \mathrm{~cm}$ were exposed to sunlight for 3 months at room temperature to obtain polymeric linoleic acid form. After 3 months, a viscous liquid with a polymer gel film layer on the surface was obtained. The resulting polymeric fatty acids were filtered after being kept in chloroform for $24 \mathrm{~h}$. This product was treated with diethanol amine to obtain hydroxylated polymeric linoleic fatty acid polymers. Then, hydroxylated polymeric fatty acids were characterized by 1H-NMR, FT-IR and GPC analyses. Molecular weight of the hydroxylated polymeric linoleic acid is PLina-OH: $970 \mathrm{Da}$ (PDI: 2.33). After the peroxide and epoxide groups were opened by treatment with diethanolamine with PLina, the hydroxylation step was completed. Diethanol amine was converted to a maximum of two fatty acids repeating units by cleaving the fatty acid. Therefore, molecular weight is decreased. In the FTIR spectrum (in Fig. 3.), the peak around at $3300 \mathrm{~cm}^{-1}$ belongs to $\left(-\mathrm{OH},-\mathrm{NH}_{2},-\mathrm{NH}\right)$ groups, $1615 \mathrm{~cm}^{-1}$ is the carbonyl peak bounds to the amide group, and peak at $1046 \mathrm{~cm}^{-1}$ is $(-\mathrm{C}-\mathrm{O})$.

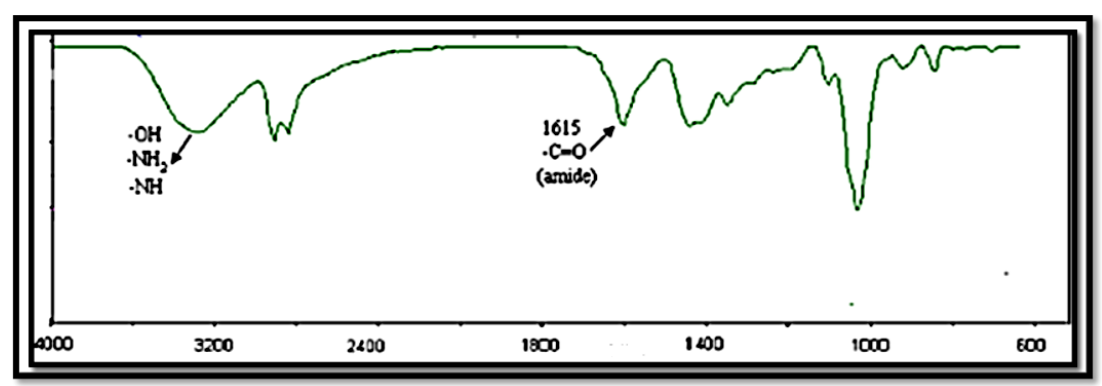

Figure 3. FT-IR spectra of PLinaOH

${ }^{1} \mathrm{H}-\mathrm{NMR}$ results of PLinaOH are shown in Fig. 4. According to this, functional groups of PLinaOH and their chemical shifts are as follows, respectively: $\left(-\mathrm{N}_{-}-\mathrm{CH}_{2}-\mathrm{CH}_{2}-\mathrm{OH}\right)$ at $2.7 \mathrm{ppm}$, (-CO-) at 4.1 ppm and (-C-OH) at 3.5-3.8 ppm. 


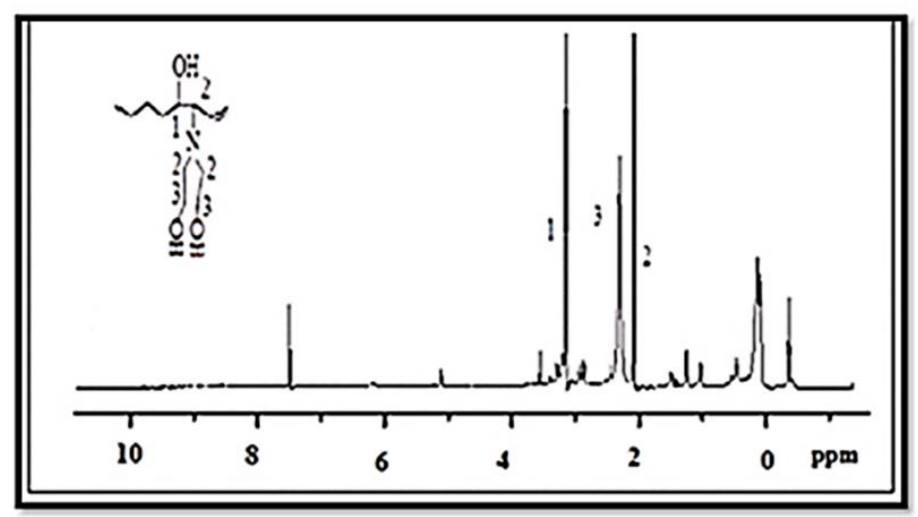

Figure 4. 1H-NMR spectra of PLinaOH

In this study, polymerization of synthesized PLinaOH-HEMA cryogels was carried out at $-18{ }^{\circ} \mathrm{C}$ via cryo-polymerizations of HEMA in presence of PLinaOH and MBAA. PLinaOH-HEMA cryogels, which were incubated at this temperature for $24 \mathrm{~h}$, were taken to room temperature conditions at the end of this period. Cylindrical shaped cryogels were obtained in an elastic structure and opaque appearance in accordance with the nature of cryogels [52]. On the other hand, with the increase in the concentration of hydroxylated polymeric oil entering the cryogel structure, the color of the cryogels changed from white to dark yellow. Optical images of cryogels can be seen in Fig. 5.

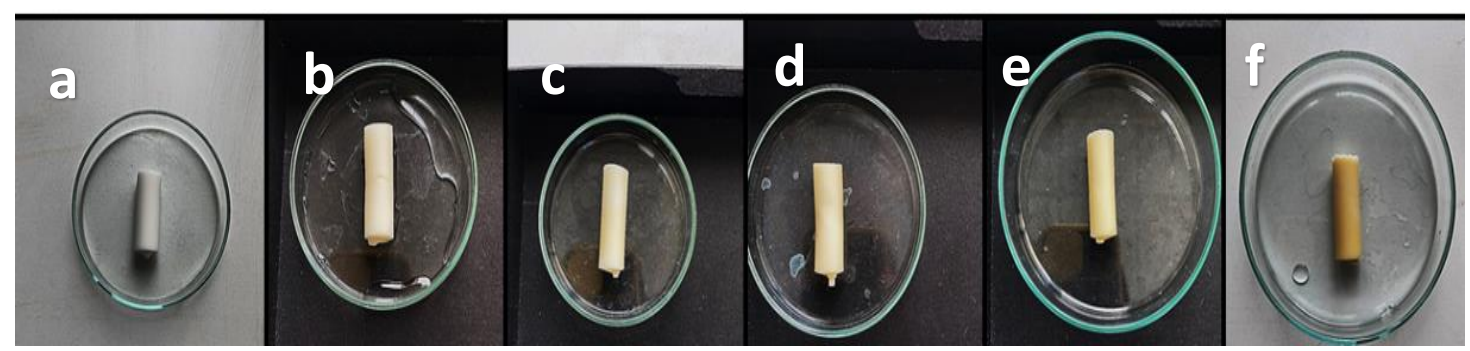

Figure 5. Optical images of PLinaOH-HEMA series cryogel

The FTIR spectra of the unmodified (pure) HEMA and PLinaOH-HEMA cryogels can be seen in Fig. 6. According to this spectrum, there are characteristic peaks are including, $3280 \mathrm{~cm}^{-1}$ region $(\mathrm{OH}$ stretch), $2940 \mathrm{~cm}^{-1}$ (CH alkyl stretches), $1716 \mathrm{~cm}^{-1}$ (C=O stretch) and $1160 \mathrm{~cm}^{-1}$ (C-O stretch) bands. For the characteristic bands of polymeric linoleic acid, the most prominent ones are alkyl peaks. In particular, as the concentration of the fatty acid increases, the alkyl peaks become more pronounced. The hydroxyl tip and some other peaks could not be clearly distinguished as they could peak in similar regions with the pure HEMA cryogel. 


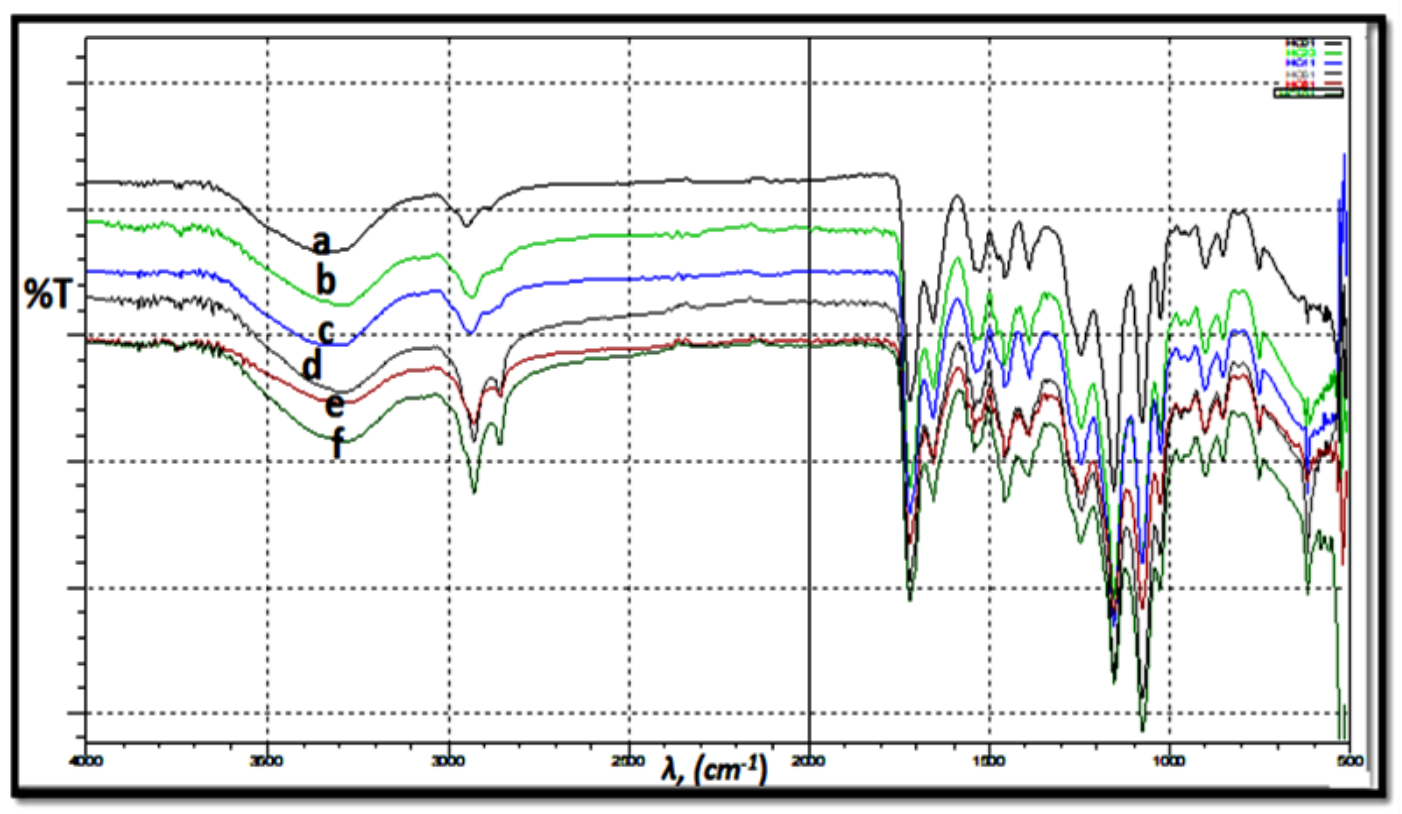

Figure 6. FTIR spectra of PLinaOH-HEMA cryogel series; (a: HCO, b: HC2, $\boldsymbol{c}: H C: 4, \boldsymbol{d}: H C 6, \boldsymbol{e}: H C 8$ and $f: H C 10)$

Fig. 7. presents SEM images of cryogels. SEM images were obtained to examine the surface morphology of the cryogels. A porous structure is formed as a result of the melting of ice crystals formed during cryogelation using water as a solvent. These images clearly show that the cryogels have a highly macroporous structure. The synthesized cryogels appear to have a smooth and uniform wall surface and interconnected flow channels. According to the size distribution of the pores $(1-100 \mu \mathrm{m})$, the structure contains micro- and macro-pores together. This makes the column flow dynamics of cryogels very smooth and their use for adsorption-desorption purposes. Despite the inclusion of polymeric hydroxylated fatty acids used in this study, no large deformation is observed in the porous structure of the cryogels. 

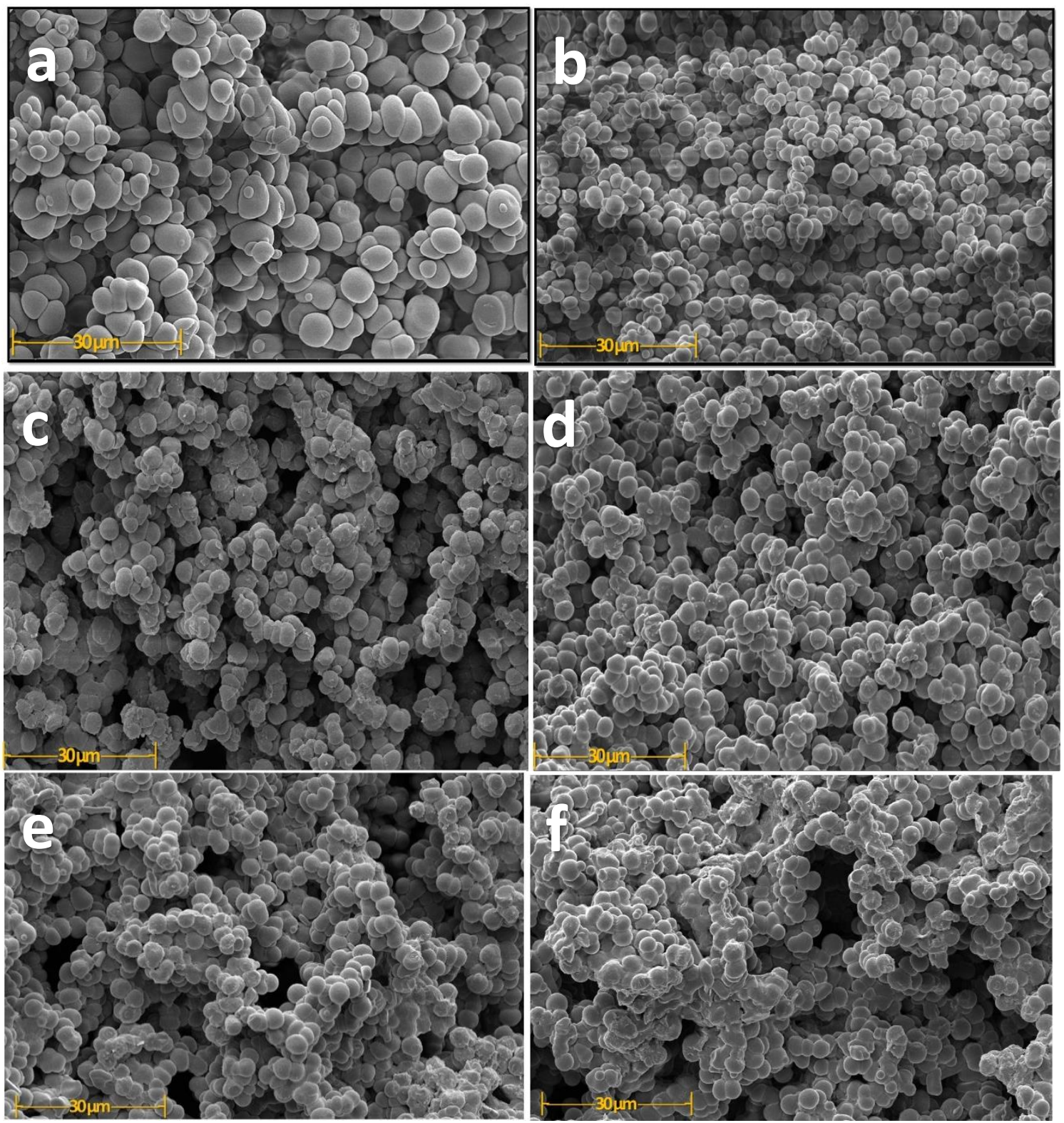

Figure 7. SEM images of PLinaOH-HEMA cryogel series; $(\boldsymbol{a}): H C O,(\boldsymbol{b}): H C 2,(\boldsymbol{c}): H C: 4,(\boldsymbol{d}): H C 6,(\boldsymbol{e}): H C 8$ and (f): $\mathrm{HClO}$

PLinaOH-HEMA and pure HEMA cryogels were investigated in the range of between 0-800 ${ }^{\circ} \mathrm{C}$ with a thermal gravimetric analyzer, and the diagrams for results of the cryogels mass losses are shown in Fig. 8, respectively. In these diagrams, thermogravimetric analysis (TGA) curves provide data on the mass losses resulting from the heating process, and the differential thermal analysis (DTA) curves provide data on the examination of the heat receiving (endothermic) and exothermic (exothermic) properties of the reactions. The mass loss stability of HEMA-based cryogels with increasing temperature appears similar. However, it is observed that the thermal life of cryogels increases with the increase in the amount of organic residues in the cryogel content. Also, looking at the DTA graphs of all cryogels, it can be assumed that the degradation (decomposition) reactions of cryogels under the influence of temperature are endothermic. 

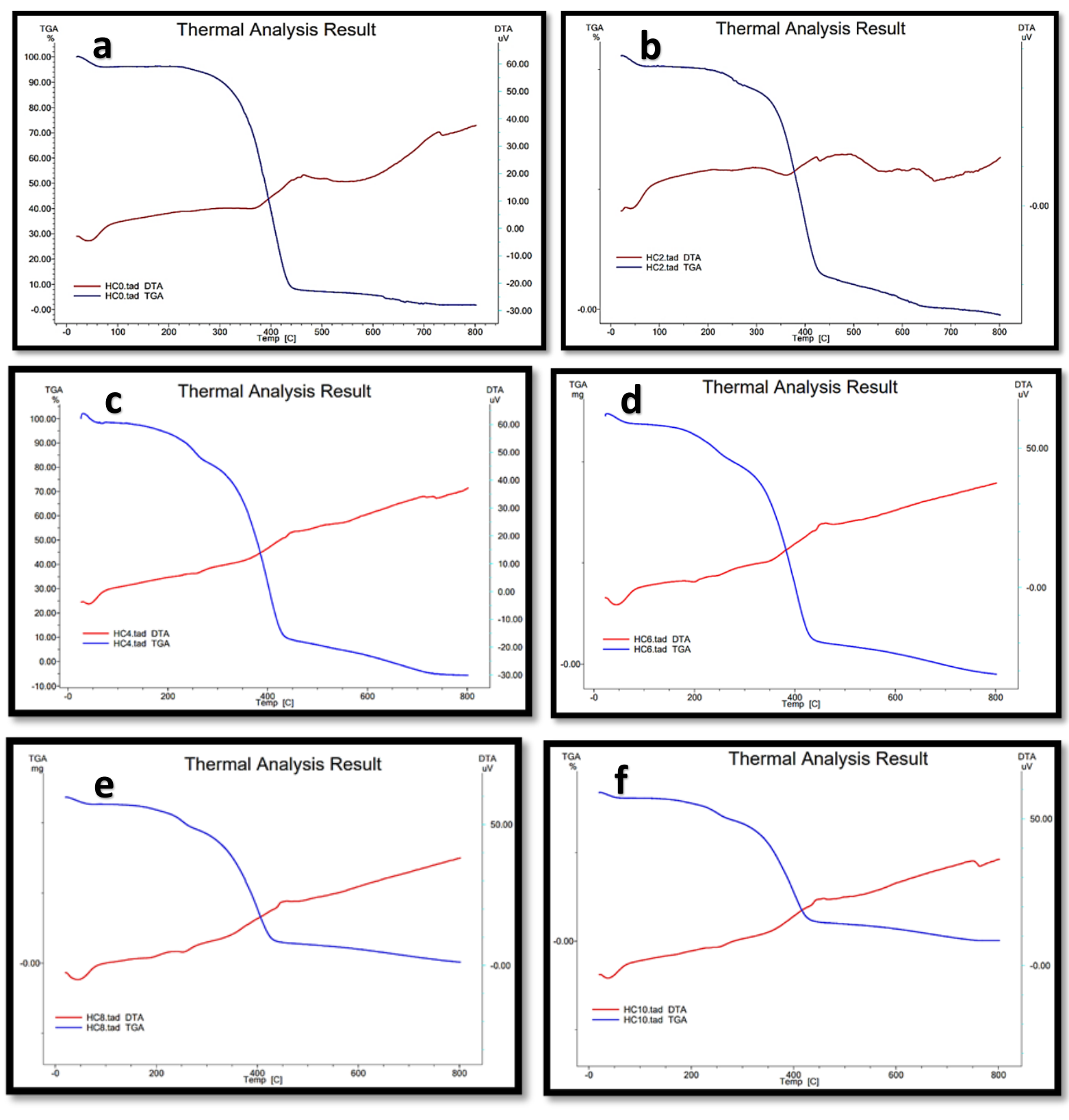

Figure 8. TGA/DSC diagrams of PLinaOH-HEMA cryogel series; (a): HCO, (b): HC2,(c): HC:4,(d): HC6, (e): HC8 and (f): HClO)

Swelling properties of cryogels are very important in terms of their usability in many fields, especially in biomedical fields. HEMA-based cryogels have the ability to high rate uptake of water thanks to their hydrophilic structure [53]. HEMA cryogels have a reticulated porous structure thanks to their cross-linking with MBAA. So, HEMA-based cryogels have the ability to absorb water at a high rate in their structure. In this study, swelling properties of HEMA-based cryogels prepared by adding different amounts of PLinaOH were investigated. Among of cryogels, the highest water uptaking capacity was HCO. On the other hand, as the PLinaOH content of HEMA-based cryogels increased, swelling test results decreased. Because, although PLina is included in the hydroxylated form, the length of the straight chain structure of linoleic acid contributes more to hydrophobicity of cryogel. However, this decrease did not occur in large proportions, the flexible structure of the cryogels was preserved. In this context, it can be said that hydrophobic properties of the synthesized cryogels have been improved. Porosity is one of the parameters that can directly affect the adsorption-based applications of cryogels. Therefore, macroporosity degree of cryogels is a practical and rapid method 
that can give an idea for the adsorpsiton based biomedical usability of the prepared cryogel. According to the analysis of macroporosity of $\mathrm{HC}$ series cryogels, it is observed that the percentage of macroporosity decreases for cryogels with increased polymeric fatty acid content. This is because PLinaOH may have been involved in the structure without direct bonding with HEMA. Swelling behavior of cryogels has been investigated in some other solvents with different polarities. In this context, n-hexane, toluene, chloroform, methanol, and dimethyl sulfoxide were used. If the polarity of the solvents increased, the swelling ratio of the $\mathrm{HO}$ sample with the highest hydrophilicity was determined as the highest. In addition, the cryogels reached the highest swelling values in DMSO, which has the highest dielectric constant and polarity among the existing solutions. This is supported by the results of a previous study [47]. Since cryogels are hydrophilic structures, it has been observed that although swelling rates are high in solvents containing hydrophilic groups, they can absorb liquid in organic solvents [19]. In addition, hydrophobic interactions may have come to the fore in solvents such as n-hexane and toluene, therefore, swelling values in these solvents increased with the condensation of the fatty acid content in PLinaOH-HEMA cryogels. Swelling characterizations of cryogels are presented in Table 1., also swelling uptake results for all cryogels in other solvents are presented in Table 2. Optical images of cryogels in both states (dried and swollen in water) are shown in Fig. 9, respectively.

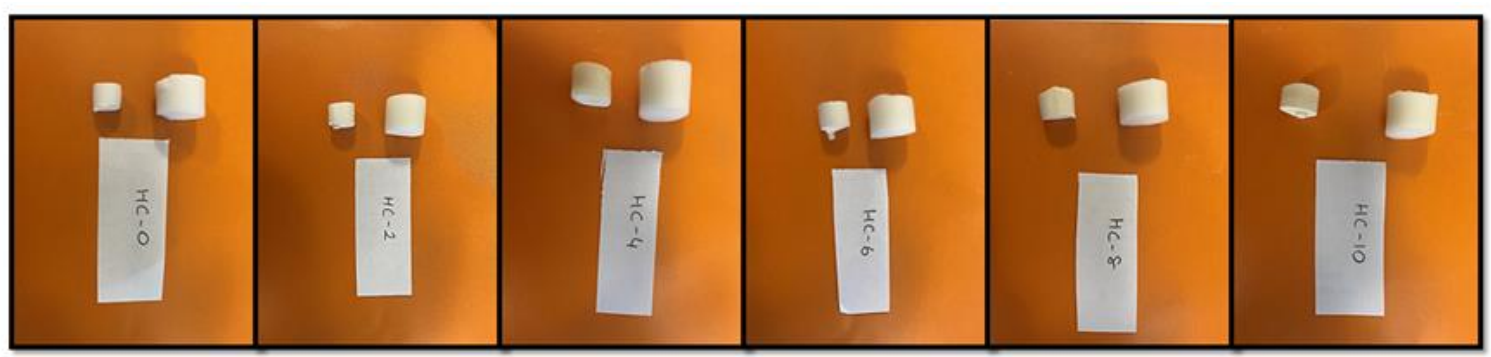

Figure 9. Optical images of cryogels in both states (dried and swollen states in water)

Table 1. Swelling characterization results of cryogels

\begin{tabular}{|c|c|c|c|}
\hline cryogels & $\frac{\frac{\text { Equilibrium }}{\text { swelling degree }(S)}}{\underline{\%}}$ & $\frac{\text { Swelling rate }}{\underline{\%}}$ & $\frac{\text { Macroporosity }}{\frac{\%}{\underline{y}}}$ \\
\hline HCO (pure HEMA) & 5.90 & 590.08 & 80.5 \\
\hline HC2 & 5.80 & 580.40 & 78.8 \\
\hline HC4 & 5.68 & 568.02 & 75.6 \\
\hline HC6 & 5.52 & 552.08 & 73.5 \\
\hline HC8 & 5.22 & 522.47 & 71.2 \\
\hline HC10 & 5.00 & 500.10 & 70.2 \\
\hline
\end{tabular}

Table 2. Swelling rates (\%) of cryogels in other solvents

\begin{tabular}{cccccc}
\hline cryogels & n-hexane & toluene & chloroform & methanol & DMSO \\
\hline HC0 (pure HEMA) & 145.80 & 165.43 & 190.7 & 577.33 & 1037.85 \\
\hline HC2 & 158.44 & 167.16 & 250.6 & 495.01 & 1037.5 \\
\hline HC4 & 160.50 & 180.03 & 293.67 & 501.77 & 1168.6 \\
\hline HC6 & 171.88 & 198.57 & 300.54 & 508.53 & 1190.8 \\
\hline HC8 & 183.80 & 205.54 & 312.5 & 520.20 & 1207.6 \\
\hline HC10 & 188.32 & 210.20 & 335.6 & 540.08 & 1260.3 \\
\hline
\end{tabular}

Parameters for the determination of swelling rate of cryogels in water; swelling rate constant $k_{s}$, initial swelling speed $r$ and theoretical equilibrium swelling value $S_{\max }$ are calculated with help of Eq (4) 
and, and Eq (5) are presented in Table 3. In order to calculate these values, the slopes and cut points of the lines obtained from the $\mathrm{t} / \mathrm{S}-\mathrm{t}$ graphs presented in Fig. 10 below were used.

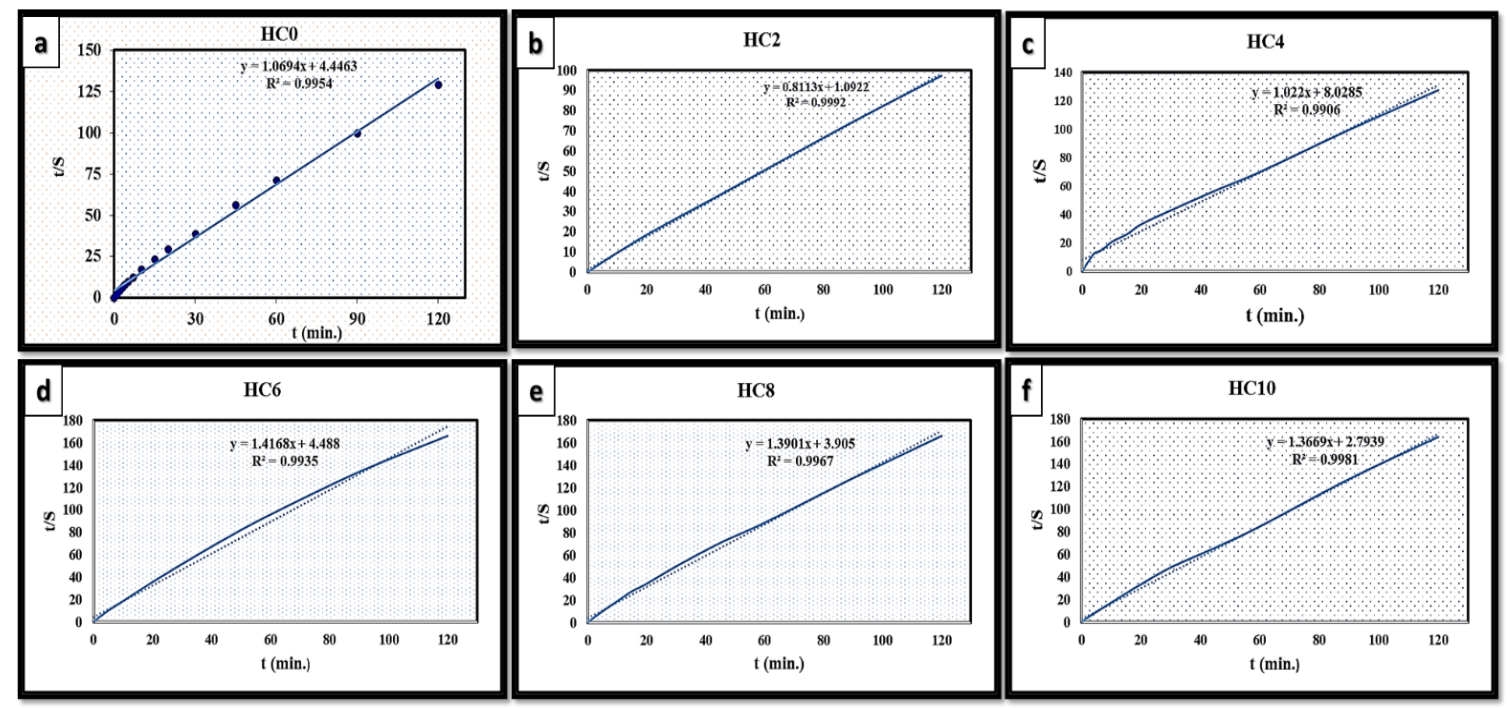

Figure 10. Swelling kinetics curves of cryogels

Table 3. Parameters for swelling kinetics of cryogels

\begin{tabular}{cccc}
\hline cryogels & $\boldsymbol{r}_{\mathbf{0}}$ & $\boldsymbol{k}_{\boldsymbol{s}} \times \mathbf{1 0}^{\mathbf{6}}$ & $\boldsymbol{S}_{\boldsymbol{\text { max }}}$ (teoritical) \\
\hline HC0 & 0.2249 & 4.316 & 935.51 \\
\hline HC2 & 0.915 & 1.630 & 1221 \\
\hline HC4 & 0.1245 & 7.671 & 977.51 \\
\hline HC6 & 0.2228 & 2.236 & 705.81 \\
\hline HC8 & 0.256 & 7.54 & 719.37 \\
\hline HC10 & 0.3579 & 0.153 & 731.5 \\
\hline
\end{tabular}

\section{DISCUSSION}

Cryogels are one of the most interesting topics of the gel family in recent years. In this study, it is aimed to create a new type of cryogel to contribute to the new generation polymeric systems in the literature. For this purpose, semi-IPN PLinaOH-HEMA cryogel was synthesized as a result of cryopolymerization between hydroxylated form of polymeric linoleic acid, which has biodegradable feature and renewable resources-based and HEMA monomer in same cryogel matrix. As a result of the swelling tests of the PLinaOH-HEMA cryogel, the hydroxyl form of the polymeric linoleic fatty acid formed a certain hydrophobic environment in the cryogel against the hydrophilic character of the HEMA monomer. In particular, with the increase of PLinaOH concentration in the cryogel, decreases were observed for swelling values of cryogels, although not as much as abnormal values, but the spongy and elastic morphological structure of the cryogels was not affected. This study shows that polymeric fatty acids and their hydroxylated derivatives have been reported in the literature for applications to improve the hydrophobic character of cryogels, and it is believed to hold potential for future applications, especially in the biomedical and biotechnological fields.

ACKNOWLEDGEMENT: This study was supported by Düzce University Scientific Research Projects (Grant/Award Number: 2019.05.03.1024). 


\section{REFERENCES}

[1] L. Z. Rogovina, V. G. Vasil'ev, and E. E. Braudo, "Definition of the concept of polymer gel," Polym. Sci. - Ser. C, vol. 50, no. 1, pp. 85-92, 2008.

[2] J. Jagur-Grodzinski, "Polymeric gels and hydrogels for biomedical and pharmaceutical applications," Polymers for Advanced Technologies, vol. 21, no. 1. pp. 27-47, 2010.

[3] N. Sahiner, "Soft and flexible hydrogel templates of different sizes and various functionalities for metal nanoparticle preparation and their use in catalysis," Progress in Polymer Science, vol. 38, no. 9. Pergamon, pp. 1329-1356, Sep. 01, 2013.

[4] F. Horkay and J. F. Douglas, "Polymer Gels: Basics, Challenges, and Perspectives," 2018. Accessed: Jun. 22, 2021. [Online]. Available: https://pubs.acs.org/sharingguidelines.

[5] J. Kopeček, "Polymer chemistry: Swell gels," Nature, vol. 417, no. 6887. Nature Publishing Group, pp. 388-391, May 23, 2002.

[6] V. I. Lozinsky, "Cryogels on the basis of natural and synthetic polymers: Preparation, properties and application," Usp. Khim., vol. 71, no. 6, pp. 579-584, 2002.

[7] K. Ito, "Novel cross-linking concept of polymer network: Synthesis, structure, and properties of slide-ring gels with freely movable junctions," Polym. J., vol. 39, no. 6, pp. 489-499, 2007.

[8] V. I. Lozinsky and O. Okay, "Basic Principles of Cryotropic Gelation," Adv. Polym. Sci., vol. 263, pp. 49-101, 2014.

[9] F. M. Plleva, I. Y. Galaev, and B. Mattiasson, "Macroporous gels prepared at subzero temperatures as novel materials for chromatography of particulate-containing fluids and cell culture applications," Journal of Separation Science, vol. 30, no. 11. pp. 1657-1671, 2007.

[10] M. Zhai, F. Ma, J. Li, B. Wan, and N. Yu, "Preparation and properties of cryogel based on poly(hydroxypropyl methacrylate)," J. Biomater. Sci. Polym. Ed., vol. 29, no. 12, pp. 1401-1425, 2018.

[11] F. Ak, Z. Oztoprak, I. Karakutuk, and O. Okay, "Macroporous Silk Fibroin Cryogels," Biomacromolecules, vol. 14, no. 3, pp. 719-727, 2013.

[12] S. A. Bencherif, R. W. Sands, O. A. Ali, W. A. Ali, S. A. Lewin, T. M. Braschler, T. Shih, C. S. Verbeke, D. Bhatta, G. Dranoff, D. J. Mooney, "Injectable cryogel-based whole-cell cancer vaccines," Nat. Commun., vol. 6, no. 1, pp. 1-13, 2015.

[13] T. Santos, A.Brito, R.Boto, P.Sousa, P.Almeida, C.Cruz and C.Tomaz, "Influenza DNA vaccine purification using pHEMA cryogel support," Sep.Purif. Technol., vol. 206, pp. 192-198, 2018.

[14] T. D. Luong, M. Zoughaib, R. Garifullin, S. Kuznetsova, M. O. Guler, and T. I. Abdullin, "In Situ functionalization of Poly(hydroxyethyl methacrylate) Cryogels with Oligopeptides via $\beta$ Cyclodextrin-Adamantane Complexation for Studying Cell-Instructive Peptide Environment," ACS Appl. Bio Mater., vol. 3, no. 2, pp. 1116-1128, 2020. 
[15] A. Cecilia, A. Baecker, E. Hamann, A. Rack, T. van de Kamp, F.J. Gruhl, R.Hofmann, J.Moosmann, S. Hahn, J. Kashef, S. Bauer, T. Farago, L. Helfen, and T. Baumbach,, "Optimizing structural and mechanical properties of cryogel scaffolds for use in prostate cancer cell culturing," Mater. Sci. Eng. C, vol. 71, pp. 465-472, 2017.

[16] T. Kangkamano, A. Numnuam, W. Limbut, P. Kanatharana, and P. Thavarungkul, "Chitosan cryogel with embedded gold nanoparticles decorated multiwalled carbon nanotubes modified electrode for highly sensitive flow based non-enzymatic glucose sensor," Sensors Actuators, B Chem., vol. 246, pp. 854-863, 2017.

[17] Z. Haider, A. Haleem, R. u S. Ahmad, U. Farooq, L. Shi, U. P. Clever, K. Memon, A. Fareed, I. Khan, M. K. Mbogba, S. M. Chapal Hossain, F. Farooq, W. Ali, M. Abid, A. Qadir, W. He, J. Luo, and G. Zhao, "Highly porous polymer cryogel based tribopositive material for high performance triboelectric nanogenerators," Nano Energy, vol. 68, p. 104294, 2020.

[18] M. D. Stanescu, S. Gavrilas, R. Ludwig, D. Haltrich, and V. I. Lozinsky, "Preparation of immobilized Trametes pubescens laccase on a cryogel-type polymeric carrier and application of the biocatalyst to apple juice phenolic compounds oxidation," Eur. Food Res. Technol., vol. 234, no. 4, pp. 655-662, 2012.

[19] M. Çadırc1, K. Şarkaya, and A. Allı, "Dielectric properties of CdSe quantum dots-loaded cryogel for potential future electronic applications," Mater. Sci. Semicond. Process., vol. 119, p. $105269,2020$.

[20] T. Shimizu, M. Masuda, and H. Minamikawa, "Supramolecular nanotube architectures based on amphiphilic molecules," Chemical Reviews, vol. 105, no. 4. American Chemical Society , pp. 1401-1443, 2005.

[21] C. XiaoMing, D. Wei, and Z. XianRen, "SCIENCE CHINA Chemistry Self-assembly of amphiphilic molecules: A review on the recent computer simulation results," vol. 53, no. 9, pp. 1853 1861, 2010.

[22] G. Galli and E. Martinelli, "Amphiphilic Polymer Platforms: Surface Engineering of Films for Marine Antibiofouling," Macromol. Rapid Commun., vol. 38, no. 8, p. 1600704, 2017.

[23] C. S. Patrickios and T. K. Georgiou, "Covalent amphiphilic polymer networks," Current Opinion in Colloid and Interface Science, vol. 8, no. 1. Elsevier BV, pp. 76-85, Mar. 01, 2003.

[24] S. Zarzhitsky, H. Edri, Z. Azoulay, I. Cohen, Y. Ventura, A. Gitelman, and H. Rapaport, "The effect of $\mathrm{pH}$ and calcium ions on the stability of amphiphilic and anionic $\beta$-sheet peptide hydrogels," Biopolymers, vol. 100, no. 6, pp. 760-772, 2013.

[25] X. R. Zhou, R. Ge, and S. Z. Luo, "Self-assembly of pH and calcium dual-responsive peptide amphiphilic hydrogel,” J. Pept. Sci., vol. 19, no. 12, pp. 737-744, 2013.

[26] W. Ha, J. Yu, X. Y. Song, J. Chen, and Y. P. Shi, "Tunable temperature-responsive supramolecular hydrogels formed by prodrugs as a codelivery system," ACS Appl. Mater. Interfaces, vol. 6, no. 13, pp. 10623-10630, 2014.

[27] M. H. Hsiao, M.Larsson, A. Larsson, H. Evenbratt, Y. Y. Chen, Y. Y. Chen, and D. M. Liu, "Design and characterization of a novel amphiphilic chitosan nanocapsule based thermo-gelling biogel with sustained in vivo release of the hydrophilic anti-epilepsy drug ethosuximide," J. Control.

Release, vol. 161, no. 3, pp. 942-948, 2012. 
[28] W. C. Huang, S. Y. Chen, and D. M. Liu, "An amphiphilic silicone-modified polysaccharide molecular hybrid with in situ forming of hierarchical superporous architecture upon swelling," Soft Matter, vol. 8, no. 42, pp. 10868-10876, 2012.

[29] S. Song, L. Feng, A. Song, and J. Hao, "Room-temperature super hydrogel as dye adsorption agent," J. Phys. Chem. B, vol. 116, no. 42, pp. 12850-12856, 2012.

[30] S. Das, P. Pandey, S. Mohanty, and S. K. Nayak, "Insight on Castor Oil Based Polyurethane and Nanocomposites: Recent Trends and Development," Polymer - Plastics Technology and Engineering, vol. 56, no. 14. Taylor and Francis Inc., pp. 1556-1585, Sep. 22, 2017.

[31] P. Anastas and N. Eghbali, "Green Chemistry: Principles and Practice," Chem. Soc. Rev., vol. 39, no. 1, pp. 301-312, 2010.

[32] M. A. Sawpan, "Polyurethanes from vegetable oils and applications: a review," J. Polym. Res. 2018 258, vol. 25, no. 8, pp. 1-15, 2018.

[33] H.-M. Kim, H.-R. Kim, C. T. Hou, Beom, and S. Kim, "Biodegradable Photo-Crosslinked Thin Polymer Networks Based on Vegetable Oil Hydroxy Fatty Acids," doi: 10.1007/s11746-010 1634-6.

[34] R. L. Shogren, Z. Petrovic, Z. Liu, and S. Z. Erhan, "Biodegradation behavior of some vegetable oil-based polymers," J. Polym. Environ., vol. 12, no. 3, pp. 173-178, 2004.

[35] B. Hazer, "Chemical Modification of Synthetic and Biosynthetic Polyesters," in Biopolymers Online, Wiley, 2002.

[36] P. S. Sathiskumar and G. Madras, "Synthesis, characterization, degradation of biodegradable castor oil based polyesters," Polym. Degrad. Stab., vol. 96, no. 9, pp. 1695-1704, 2011.

[37] S. Miao, P. Wang, Z. Su, and S. Zhang, "Vegetable-oil-based polymers as future polymeric biomaterials," Acta Biomaterialia, vol. 10, no. 4. Elsevier BV, pp. 1692-1704, Apr. 01, 2014.

[38] G. Acik, M. Kamaci, C. Altinkok, H. R. F. Karabulut, and M. A. Tasdelen, "Synthesis and properties of soybean oil-based biodegradable polyurethane films," Prog. Org. Coatings, vol. 123, pp. 261-266, 2018.

[39] B. Das, U. Konwar, M. Mandal, and N. Karak, "Sunflower oil based biodegradable hyperbranched polyurethane as a thin film material," Ind. Crops Prod., vol. 44, pp. 396-404, 2013.

[40] B. Çakmakli, B. Hazer, T. Erdoğan, and A. G. Mutlu, "DNA adsorption and dynamic mechanical analysis of polymeric oil/oil acid copolymers," J. Polym. Res., vol. 20, no. 3, pp. 1-11, 2013.

[41] A. Alli and B. Hazer, "Synthesis and characterization of poly(N-isopropyl acryl amide)-g poly(LINOLEIC ACID)/poly(linolenic acid) graft copolymers," JAOCS, J. Am. Oil Chem. Soc., vol. 88, no. 2, pp. 255-263, 2011.

[42] A. All and B. Hazer, "Poly(N-isopropylacrylamide) thermoresponsive cross-linked conjugates containing polymeric soybean oil and/or polypropylene glycol," Eur. Polym. J., vol. 44, no. 6, pp. 1701-1713, 2008.

[43] E. Isikci Koca, G. Bozdag, G. Cayli, D. Kazan, and P. Cakir Hatir, "Thermoresponsive hydrogels based on renewable resources," J. Appl. Polym. Sci., vol. 137, no. 28, 2020. 
[44] V. K. Singh, Sowmya, R. Kunal, A. Anis, Dillip, and K. Pradhan, "Olive oil based novel thermo-reversible emulsion hydrogels for controlled delivery applications," doi: 10.1007/s10856-013 5112-1.

[45] I. N. Savina, V.Cnudde, S. D'Hollander, L. V. Hoorebeke, B. Mattiasson, I. Y. Galaev, and F. D. Prez,, "Cryogels from poly(2-hydroxyethyl methacrylate): Macroporous, interconnected materials with potential as cell scaffolds," Soft Matter, vol. 3, no. 9, pp. 1176-1184, 2007.

[46] E. Brynda, M. Houska, J. Kysilka, M. Pradny, P. Lesny, P. Jendelova, J. Michalek, and E. Sykova, "Surface modification of hydrogels based on poly(2-hydroxyethylmethacrylate) with extracellular matrix proteins," doi: 10.1007/s10856-008-3625-9.

[47] K. Şarkaya and A. All1, "Synthesis and characterization of cryogels of p(HEMA-N vinylformamide) and p(HEMA-N-Vinylpyrrolidone) for chemical release behaviour," J. Porous Mater., vol. 28, no. 3, pp. 853-865, 2021.

[48] E. Karadağ and Ö. B. Üzüm, "A study on water and dye sorption capacities of novel ternary acrylamide/sodium acrylate/PEG semi IPN hydrogels," Polym. Bull. 2011 685, vol. 68, no. 5, pp. 1357-1368, 2011.

[49] K. Şarkaya, M. Bakhshpour, and A. Denizli, "Ag ${ }^{+}$ions imprinted cryogels for selective removal of silver ions from aqueous solutions," Sep. Sci. Technol., pp. 1-12, 2018.

[50] N. Kathuria, A. Tripathi, K. K. Kar, and A. Kumar, "Synthesis and characterization of elastic and macroporous chitosan-gelatin cryogels for tissue engineering," Acta Biomater., vol. 5, no. 1, pp. 406-418, 2009.

[51] Ö. B. Üzüm and E. Karadağ, "Equilibrium Swelling Studies of Chemically Cross-Linked Highly Swollen Acrylamide-Sodium Acrylate Hydrogels in Various Water-Solvent Mixtures," http://dx.doi.org/10.1080/03602551003664537, vol. 49, no. 6, pp. 609-616, 2010.

[52] V. I. Lozinsky, I. Y. Galaev, F. M. Plieva, I. N. Savina, H. Jungvid, and B. Mattiasson, "Polymeric cryogels as promising materials of biotechnological interest," Trends Biotechnol., vol. 21, no. 10, pp. 445-451, 2003.

[53] R. Keçili, İ. Dolak, B. Ziyadanoğulları, A. Ersöz, and R. Say, "Ion imprinted cryogel-based supermacroporous traps for selective separation of cerium(III) in real samples," J. Rare Earths, vol. 36, no. 8, pp. 857-862, 2018. 